\title{
Immediate and Long-Term Effects of Qigong on Cold Intolerance in Patients with Post-Poliomyelitis Syndrome
}

\author{
Paulo Eduardo Ramos ${ }^{1}$, Gislaine Cristina Abe ${ }^{{ }^{*}}$, Márcia Pradella-Hallinan 1,2, \\ Abrahão Augusto Juviniano Quadros ${ }^{1}$, Tan Tao ${ }^{3,4}$, Acary Souza Bulle Oliveira ${ }^{1}$
}

\footnotetext{
${ }^{1}$ Department of Neurology and Neurosurgery, Department of Clinical Neurology, Division of Neuromuscular Disease Research, Clinic of Traditional Chinese Medicine, Federal University of São Paulo (UNIFESP), São Paulo, Brazil

${ }^{2}$ Department of Psychobiology, Sleep Institute, Federal University of São Paulo (UNIFESP), São Paulo, Brazil

${ }^{3}$ Tianjin University of Traditional Chinese Medicine (TUTCM), Tianjin, China

${ }^{4}$ Department of Tuina and Orthopedics, Tuina and Orthopedics Clinic, The First Teaching Hospital, Tianjin, China

Email: * gislaineabe@hotmail.com
}

How to cite this paper: Ramos, P.E., Abe, G.C., Pradella-Hallinan, M., Quadros, A.A.J., Tao, T. and Oliveira, A.S.B. (2018) Immediate and Long-Term Effects of Qigong on Cold Intolerance in Patients with PostPoliomyelitis Syndrome. Health, 10, 56-68. https://doi.org/10.4236/health.2018.101004

Received: October 19, 2017

Accepted: January 1, 2018

Published: January 4, 2018

Copyright (c) 2018 by authors and Scientific Research Publishing Inc. This work is licensed under the Creative Commons Attribution International License (CC BY 4.0).

http://creativecommons.org/licenses/by/4.0/

\begin{abstract}
Post-poliomyelitis syndrome (PPS) is a disorder in individuals who have had poliomyelitis, characterized by new muscle weakness and often associated with other symptoms, including cold intolerance (CI). Qigong is a Traditional Chinese Medicine technique to adjust energy and blood circulation. Objective: To verify the effects and late repercussions of Qigong on CI complaints in PPS patients. Methods: PPS patients $(\mathrm{n}=22,14$ females, 8 males; ages 35 60) performed Qigong exercises in 40-minute sessions, three times per week, for three consecutive months. They were evaluated at baseline, the end of treatment and every three months for a year using a visual analogue scale adapted for CI (VAS-cold). Results: The systemic VAS-cold scores exhibited significant differences between the baseline, the end of treatment and throughout 12 months of follow-up. Conclusion: The CI scores were low and bearable at the end of intervention and for the following 12 months without activity.
\end{abstract}

\section{Keywords}

Post-Poliomyelitis Syndrome, Qigong, Breathing Exercises, Public Health

\section{Introduction}

Post-poliomyelitis syndrome (PPS) is a disorder of the nervous system that affects people who have had poliomyelitis. PPS is characterized by new muscle 
weakness added to the residual manifestations of poliomyelitis and is often associated with other symptoms, including muscle fatigue, muscle and/or joint pain, cold intolerance (CI) and sleep disorders [1] [2] [3] [4] (see Table 1). Approximately $69.8 \%$ of individuals with PPS in Brazil exhibit CI. On clinical examination, the affected limbs are abnormally cold due to affected sympathetic nerve cells [5]. The etiology of CI has not yet been established, and there is no specific treatment for it; the affected individuals are advised to wear appropriate clothes, perform distal/proximal massages and apply local heat over short periods of time [6].

From the clinical and histological point of view, the pathophysiology of PPS involves dysfunction of the lower motor neurons. Overtraining and dysfunction of the surviving motor neurons causing disintegration of the axon terminals are the main mechanisms that cause PSS. However, compensatory mechanisms are also activated to induce muscle reinnervation, increasing the size of the motor unit. This phenomenon occurs in partially damaged axons. Exposure to stress contributes to electrophysiological changes that reduce the speed of nerve conduction, which favors early degeneration [7].

Following the publication of the "National Policy of Integrative and Complementary Practices in the Unified Health System" (Política Nacional de Práticas Integrativas e Complementares no Sistema Único de Saúde"-PNPIC-SUS) on December 2005, the National Health Council has promoted the use of

Table 1. Clinical characteristics of poliomyelitis cases study in São Paulo city.

\begin{tabular}{|c|c|}
\hline Clinical characteristics & $\%$ \\
\hline Muscle weakness & 68 \\
\hline Muscle pain & 6 \\
\hline Fatigue & 66 \\
\hline Muscle atrophy & 38 \\
\hline Fasciculation & 20 \\
\hline Dysphagia & 18 \\
\hline Neuropathy & 15 \\
\hline Respiratory problems & 6 \\
\hline Articular pain & 68 \\
\hline Cold intolerance & 40 \\
\hline Depression & 50 \\
\hline Headache & 30 \\
\hline Quadriplegia & 51 \\
\hline Triplegia & 28 \\
\hline Diplegia & 8 \\
\hline Monoplegia & 7 \\
\hline
\end{tabular}


complementary and alternative treatments by healthcare providers on a multi-professional basis. The therapies originating in China and included in the PNPIC are acupuncture, moxibustion, diet therapy, phytotherapy, physical exercises and manipulative therapies [8].

Traditional Chinese Medicine (TCM) is an Eastern healthcare practice that takes the patient's physical, mental, spiritual and environmental features into consideration, as well as his or her health-disease process [3].

In 1973, some objects were unearthed from Han (漢朝) dynasty tombs in Mawangdui (馬王堆), Zhangsha (長沙), Hunan (湖南) province, including a series of 44 gravures depicting exercises known as Daoyin. That finding represented a milestone in the history of the Chinese self-care-centered corporal arts. In 1984, excavations in Hubei (湖北) province found, among other objects, one book entitled Yinshu, written on bamboo slips and dated 186 BC, that made reference to Daoyin. Furthermore, 110 gravures were found at that site, of which 9 were duplicated, 85 provided instructions for the movement, and 50 were used as a method of treating disease [9].

The gravures described exercises performed lying down, sitting and standing. The book comprised five chapters devoted to the following subjects: 1) recovery of health under the four climates (heat, dampness, wind and cold); 2) description of the theory and practice of Daoyin; 3) the use of 45 exercises for the recovery of health; 4) the use of 24 exercises to strengthen the body; and 5) the pathophysiology, treatment and prevention of diseases [9].

This study is justified by the paramount importance of follow-up in individuals with neuromuscular disease after the end of treatment to assess the interference of treatment in the natural history of disease.

The aim of this study was to investigate the effects and late repercussions of Daoyin Qigong (DQ) relative to CI in individuals with PPS.

\section{Methods}

\subsection{Patients}

The study included 22 patients ( 8 males, 14 females) aged between 35 and 60 years with clinical diagnoses of PPS, according to criteria developed by Mulder [10]. Our study was conducted by the division of Neuromuscular Disease Research with the approval of the Ethics committee of UNIFESP, $n^{0}: 1117 / 09$, from September 2009 to December 2010, in São Paulo, Brazil.

\subsection{Allocation}

Patients were randomly selected according to their record numbers. The patients signed a consent form after being informed about the study.

\subsection{Inclusion Criteria}

We included all patients who fulfilled the definition of PPS-morbid condition in consequence of the poliomyelitis disease-and complained of CI. 


\subsection{Exclusion Criteria}

Patients with medical histories featuring diseases that could mimic PPS, patients with diagnoses of stable polio sequelae, individuals with diagnoses of peripheral vascular disorders and individuals with well-established diagnoses of PPS who were likely to experience difficulties in the execution of the exercises. Patients did not meet the definition of PPS, whose age was 60 years or older at the time of diagnosis. Avoiding the inclusion of people whose motor impairment may be due to age. Patients who fulfilled the definition of PPS and who had diseases that could also cause muscle weakness; Untreated hypothyroidism with abnormal exams; Diabetes mellitus; Anaemia; Cancer in other parts than the nervous system; Renal diseases; Hepatic diseases; Cardiopathy; Neuropathy by nerve compression; Neuropathies; Radiculopathies; Stenosis of the medullary cavity; Atrophy by disuse; Amyotrophic lateral sclerosis; Guillain-Barre syndrome; Chronic inflammatory demyelinating polyneuropathy; Nervous system tumors; Myelopathies (spinal cavity tumor, heart attack or inflammatory myelopathy); Cauda equina syndrome; Inflammatory myopathy; Muscular dystrophy; Multiple sclerosis; Stroke Parkinson's disease Diabetic amyotrophy and myasthenia gravis.

\subsection{DQ Exercises Used}

Five exercises form Yinshu (引書) [9], a book that presents 50 exercises that recover health, were selected and adapted for the sitting position. These exercises were performed along with a specific breathing technique designated as "the small circle," which consists of abdominal breathing. The exercises were applied in sessions of 40 minutes, 3 times per week for 3 consecutive months.

The first exercise, called "Seed Harvest," is an adaptation of the Mang Zhong (芒種), see Figure 1. The therapeutic aim is to encourage the decompression of the spine's intervertebral structures and specifically strengthen the adjacent muscles that promote vertebral stabilization.

The second exercise, entitled "Leading the Waist," is adapted from the exercise Yinyao (引腰), see Figure 2. Its therapeutic purpose is the decompression of the spine's intervertebral structures by relaxing and stretching and by strengthening of the adjacent muscles that promote vertebral stabilization.

The third exercise is called "Summer Solstice" and is an adaptation of the exercise Xiazhi (夏至), see Figure 3. Its therapeutic potential is to mobilize and strengthen the deep posterior muscles, including the multifidus, intertransversarius, interespinalis and rotators. These muscles lie bilaterally to the spine. In stretching, both sides are activated, whereas in rotation or lateral flexion, they are unilaterally activated.

The fourth exercise, entitled "Cloud Hands," is an adaptation of Yang shi taijiquan (楊氏太極拳), which was originally called Yunshou (雲手), see Figure 4. The therapeutic aim is to mobilize and strengthen the rotator muscles.

The fifth and last exercise of the series is called "Closure" and is based upon 


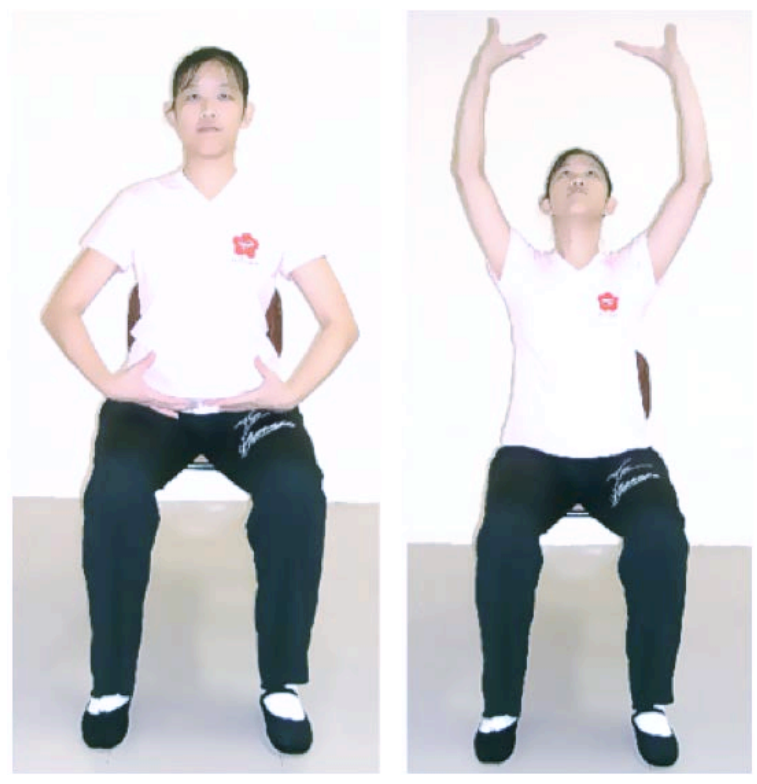

Figure 1. Seed harvest.

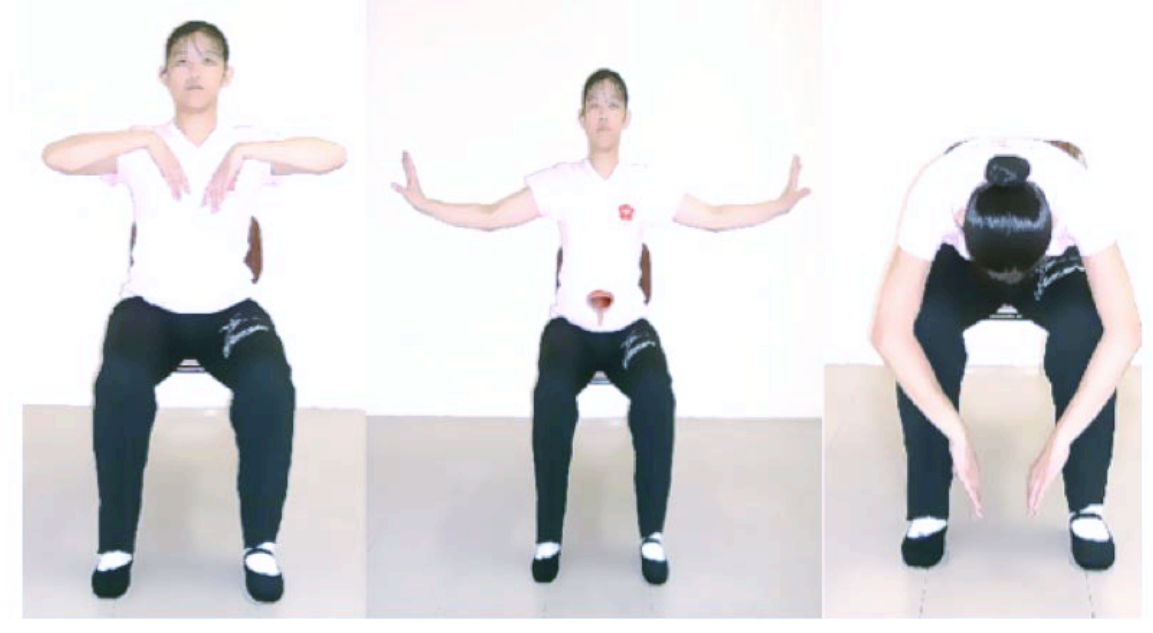

Figure 2. Leading the waist.
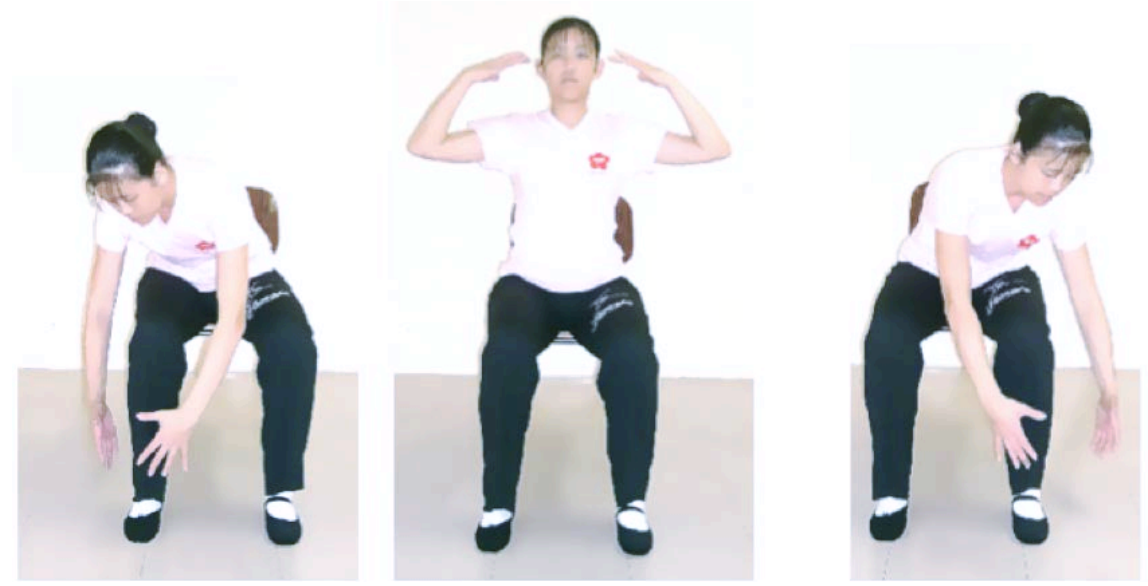

Figure 3. Summer solstice. 
the Shoushi (收勢), see Figure 5. The therapeutic goal is to mobilize and strengthen the deep posterior muscles, such as the multifidus, intertransversarius, interespinalis and rotators.

\subsection{Instructions for the Daoyin Exercises}

\subsubsection{Seed Harvest}

1) Turn your palms outward and lift them above your head, drawing a circle in the air with both hands.

2) With your torso erect, shrink it as much as possible.

3) Lift the torso and stand erect, feeling the spine straightening and your hands above your head holding up the sky.

4) Stretch your arms up as if to push up the sky.

5) Release your body; turn your palms down, and repeat.

\subsubsection{Leading the Waist}

1) Start with your back straight and your hands loose by your sides.

2) Join the backs of your hands and lift them along the center of the torso to the manubrium.
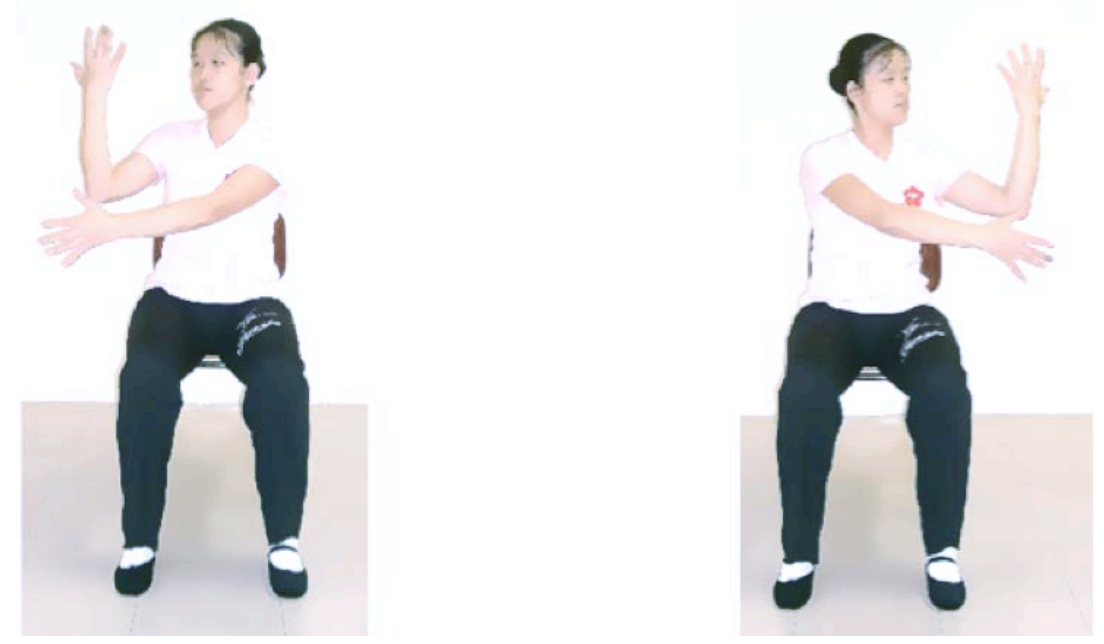

Figure 4. Cloud hands.
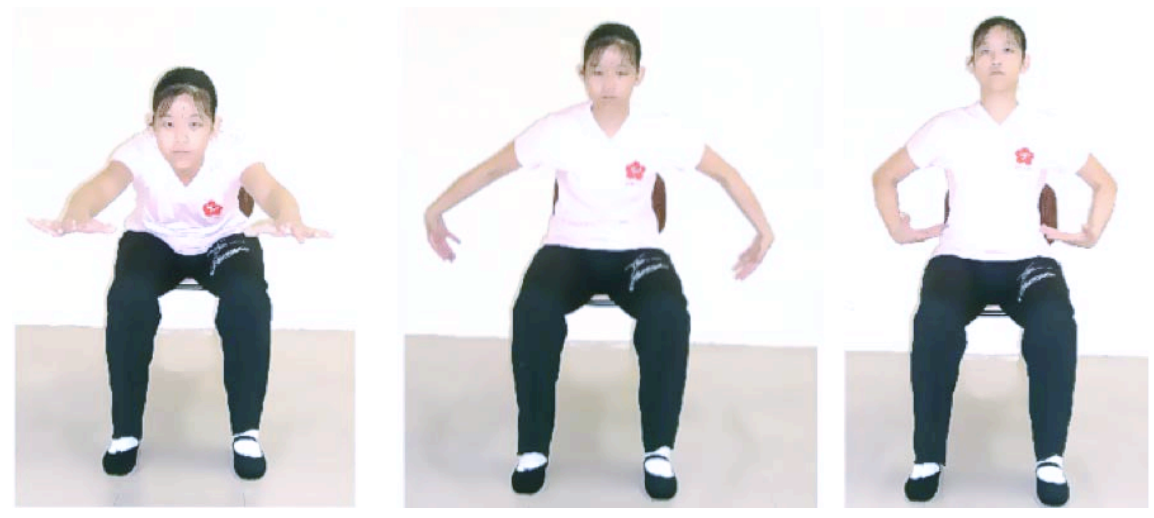

Figure 5. Closure. 
3) Open your arms outwards and stretch them. Then, slowly lower them towards your feet. Join the backs of your hands again and repeat.

\subsubsection{Summer Solstice}

1) Remain in a sitting position with your back straight.

2) Bend your torso towards your left foot with one palm along the lateral side of your leg and the other on the medial side. Then, slide both hands upward towards the corner of your eyes to touch the temporal zone with your fingertips.

3) Open your arms outwards, stretching them laterally. Then, lower them towards your right foot. Repeat on the other side.

\subsubsection{Cloud Hands}

1) Sit with your back straight and arms hanging down by your sides.

2) Lift your right arm with the palm facing down.

3) At the same time, bend the left arm into the body with the palm facing down.

4) Stretch your right arm above your head, and push down with your left palm.

5) Rotate your torso to the left, lowering your right arm while lifting your left arm.

6) Stretch your left arm above your head, and push down with your right palm.

7) Rotate your torso to the right, lowering your left arm, and return to the second movement.

\subsubsection{Closure}

1) In a sitting position, keep your back straight and hands on thighs.

2) Bend your elbows, and slide your hands along the ribs up to the xiphoid process. There, cross your fists, palms facing up, and turn them over. With the palms facing down, stretch your arms towards the sides, drawing a circle. While drawing the circle, bend your body forward as if swimming in a pool.

3) Move your hands back towards the ribs and repeat the sequence.

\subsubsection{Breathing Instructions}

Phase 1: While inhaling, relax the cervical spine slightly, shrinking the supraumbilical region while relaxing the infraumbilical region, slowly performing an anteversion of the hip. Inhalation must be performed slowly and finalized with a five-second pause.

Phase 2: While exhaling, gradually contract the abdominal muscles (external oblique and rectus abdominis) and the perineum region, straightening the back and performing a retroversion of the hip. The cervical region should also be aligned. Finalize exhalation with a five-second pause.

The tip of the tongue must touch the hard palate (connecting two important meridians: the Governing Vessel and Conception Vessel), just behind the central incisors. 


\subsection{Description of the Visual Analog Scale}

The Visual Analog Scale (VAS) is a psychometric response scale for use in questionnaires. In this case, it has been used to evaluate intolerance to cold. It consists of a 10-centimeter sliding scale on a horizontal or vertical line, with categories from "no complaint," referring to a score of zero, to "intolerant," referring to a score of ten.

The patient will draw a cross or a line (perpendicular to the scale) marking the point that represents the intensity of his/her complaint. Therefore, the intensity of sensitivity to cold and the mark position on the scale are equivalent.

Afterwards, the distance in centimeters is measured from the beginning of the scale (which corresponds to zero) to the mark, thus obtaining a numerical rating, which is recorded on the record sheet.

\subsection{Statistics}

The t-test, Levene's test, the General Linear Model and the Bonferroni post hoc test were used. The 95\% confidence intervals of the means were calculated, and the significance level was established as a p-value of 0.05 . The analysis was performed using the software SPSS V20 and Excel Office 2007.

\section{Results}

With regard to age $(\mathrm{t}(20)=1.02, \mathrm{p}=0.921)$, age at polio $(\mathrm{t}(20)=-0.31, \mathrm{p}=$ $0.434)$, polio stability $(\mathrm{t}(20)=0.40, \mathrm{p}=0.813)$, PPS period $(\mathrm{t}(20)=1.66, \mathrm{p}=$ $0.013)$ and body mass index (BMI) $(\mathrm{t}(20)=-0.142, \mathrm{p}=0.113)$, no statistically significant differences were found between the male and female participants, except for the PPS period on the t-test and Levene's test; see Table 2. In the General Linear Model, evaluations 3, 4, 5 and 6 exhibited statistically significant

Table 2. Description of the characteristics of the 22 participants.

\begin{tabular}{cccccc}
\hline Characteristics & Sex & N & Mean & Std. Deviation & Sig. \\
\hline \multirow{2}{*}{ Age } & male & 8 & 52.4 & 6.1 & \\
& female & 14 & 49.6 & 6.2 & 0.921 \\
Polio Age & male & 8 & 23.0 & 15.3 & \\
& female & 14 & 28.8 & 51.2 & 0.434 \\
Stability Polio & male & 8 & 43.4 & 8.0 & \\
& female & 14 & 41.8 & 8.6 & 0.813 \\
Period PPS & male & 8 & 9.6 & 7.0 & 0.013 \\
& female & 14 & 6.1 & 3.0 & \\
BMI & male & 8 & 25.9 & 4.8 & 0.113 \\
& female & 14 & 25.6 & 3.0 & \\
\hline
\end{tabular}

PPS = post-polio syndrome, BMI = body mass index ( $\mathrm{t}$-test for equality of means and Levene's test for equality of variances). 
differences relative to the first one, except for evaluation 5 , with adjustment for the temperature of the room in the Bonferroni post hoc test; see Table 3 and Figure 6.

\section{Discussion}

We found that following DQ training, the complaints of CI exhibited statistically significant improvement in all the participants, and the sensitivity to cold exhibited low scores and bearable levels at the end of intervention and in the evaluations performed during the following 12 months. In the study by Ramos et al.

Table 3. Correlation between the Visual Analog Scale scores at the evaluations and the first evaluation with adjustment for the environmental temperature.

\begin{tabular}{cccc}
\hline Evaluation & Mean & Std. Error & Sig. \\
\hline Evaluation I & $7.114^{\mathrm{a}}$ & 0.554 & - \\
Evaluation II & $3.159^{\mathrm{a}}$ & 0.550 & $<0.001$ \\
Evaluation III & $3.727^{\mathrm{a}}$ & 0.480 & 0.001 \\
Evaluation IV & $4.409^{\mathrm{a}}$ & 0.565 & 0.005 \\
Evaluation V & $5.977^{\mathrm{a}}$ & 0.514 & 1.000 \\
Evaluation VI & $4.591^{\mathrm{a}}$ & 0.525 & 0.023 \\
\hline
\end{tabular}

a. Covariates appearing in the model are evaluated at the following values: mean temperature $=22.33$. Sig.: relative to the first evaluation (General Linear Model).

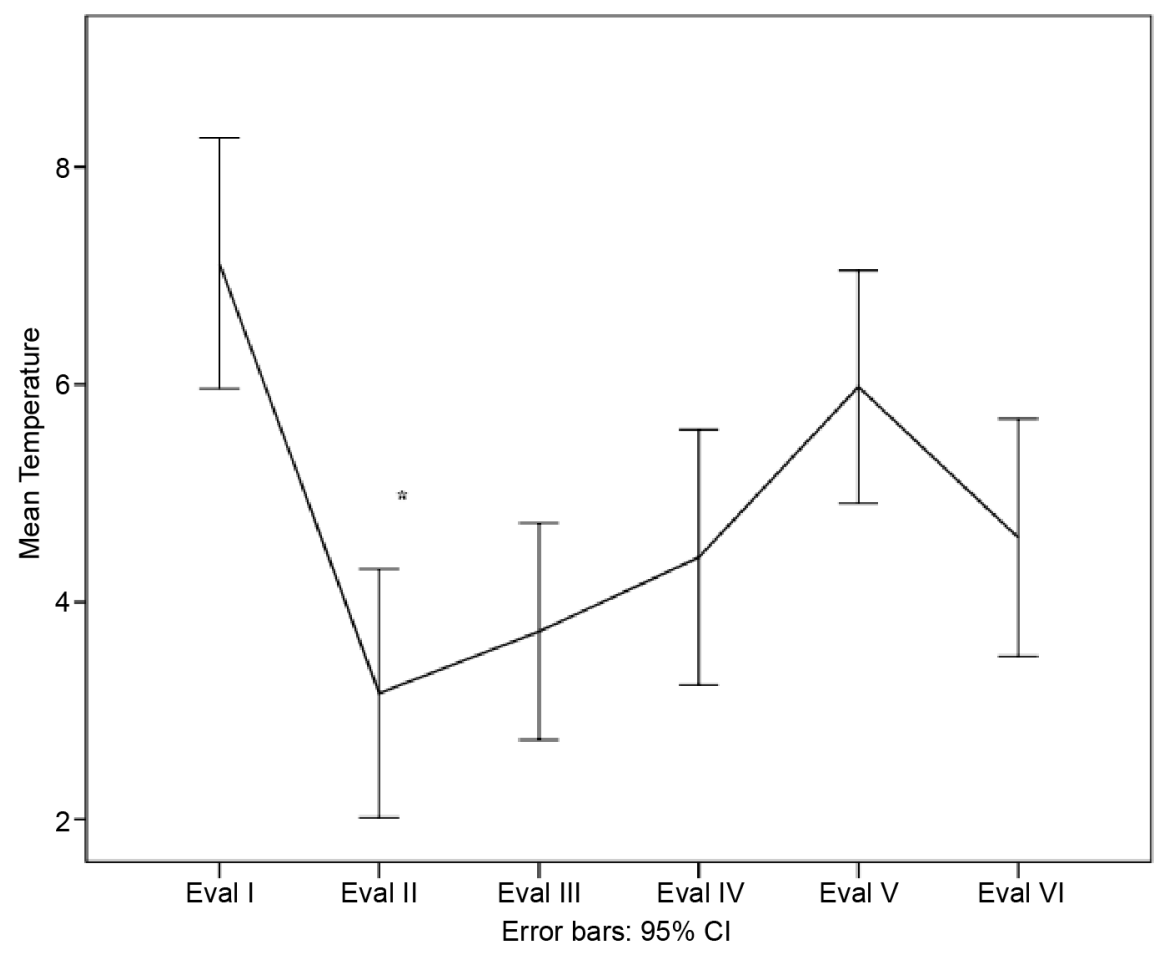

Figure 6. Effects of time on the temperature adjusted for the environmental temperature. General Linear Model (GLM). ${ }^{\star} \mathrm{p}=<0.05$; Bonferroni post hoc test compared to the first evaluation. 
(2012) [11], the participants were trained in eight exercises; however, as a function of the difficulties in memorization reported by the participants, this study trained the participants in only the five simplest and most easily reproduced DQ exercises. The results of the two studies agree.

Barbosa and Stewien (1980) analyzed the records of 1305 individuals affected by the poliovirus from 1967 to 1977 in the city of São Paulo and found that $75.3 \%$ of the cases of polio corresponded to children within the two first years of life, while $0.5 \%$ corresponded to individuals aged 15 years old or older [12]. In this study, most cases of polio had occurred within the first two years of life and the smallest fraction at age 15 years old or older (see Table 4).

There is universal agreement that systematic, planned physical activity helps to improve and restore physical functioning and to optimize the global state of the health of individuals. For patients with PPS, the practice of exercise for therapeutic or sport-related purposes requires particular attention. Low-impact activities and/or exercises performed under personal instruction, beginning with relaxation and combining free isometric exercises with resistance training and appropriate breathing processes, are indicated for most motor neuron diseases, as they are favorable for the neuroplasticity induced by functional or motor tasks [13] [14], increase the body temperature as a function of the muscle activity and trigger the release of adenosine triphosphate into arterial circulation [15]-[20]. Notwithstanding those benefits, the particularities of each individual should be considered.

Following up individuals with neuromuscular disorders after the end of treatment is of paramount importance for assessing the effect of the investigated therapy on the natural history of the disease, as well as of its residual effects as a function of inactivity time, to determine the need to repeat the intervention or interruption. In this study, the cold sensitivity scores remained low and were

Table 4. Distribution of poliomyelitis cases in the study sample by age.

\begin{tabular}{ccc}
\hline \multirow{2}{*}{ Age (years) } & \multicolumn{3}{c}{ Poliomyelitis cases } \\
\cline { 2 - 3 } & No & $\%$ \\
\hline 1 & 7 & 31.8 \\
2 & 7 & 31.8 \\
3 & 4 & 18.2 \\
4 & 2 & 9.1 \\
$0-5$ & 1 & 4.5 \\
$5-10$ & 21 & 95.5 \\
$10-15$ & - & - \\
$\geq 15$ & - & 4.5 \\
Total & 1 & 100 \\
\hline
\end{tabular}


associated with bearable levels during the evaluations performed after the end of intervention. Those findings represent a positive aspect of the investigated technique concerning the ratio of length to late effects of the treatment. However, the results at the fifth evaluation did not exhibit a significant difference compared to the baseline. We believe that this finding might be due to accumulated exposure to cold, i.e., to low winter temperatures, as the data were collected at the beginning of the spring, from September to November. The city of São Paulo, where the study was conducted, is located in the Brazilian Southeastern area, which has a humid subtropical climate with an average annual temperature ranging from $19^{\circ} \mathrm{C}$ to $27^{\circ} \mathrm{C}$. While the summer temperature might be higher than $28^{\circ} \mathrm{C}$, the average temperature in the autumn is $23^{\circ} \mathrm{C}$. In the winter, it seldom falls below $15^{\circ} \mathrm{C}$, and in the spring, it is approximately $18.2^{\circ} \mathrm{C}$ [21] [22]. The perception of the environmental temperature and the efficiency of thermoregulation, which allow for the onset of any physiological response and the resistance to cold, decrease with age, which is common in aging or inactive and sedentary individuals [23] [24] [25] [26]. Those changes are a part of the physiological changes that occur in normal aging. Individuals with PPS experience such changes earlier, including the replacement of lean mass by fat mass and hypersensitivity to cold [23]. The gradual loss of the effects of exercise over time is also relevant, as it impairs the ability to perceive the environmental temperature and the efficacy of thermoregulation against cold. The results of this study suggest that physical activity should be resumed at approximately the time when the fifth evaluation was performed to prevent complaints related to CI from increasing to the level found at the first assessment.

We suggest that DQ exerts positive effects on CI. Following up individuals with neuromuscular disorders after the end of treatment is of paramount importance for assessing the interference accomplished by the investigated therapy in the natural history of the disease. Therapeutic decision-making should consider the possible interference of the environment, especially in the case of individuals with PPS and CI. Therapeutic programs should incorporate preventive goals, monitor the patients to establish the moment when activity should be restarted and particularly stimulate self-care. Low-impact exercises contribute to the maintenance and conservation of the patients' energy and global wellbeing.

DQ exercises exhibited positive effects on the CI complaints of individuals with PPS. VAS scores relative to cold sensitivity remained low and associated with bearable levels at the end of intervention and in the evaluations performed throughout the following 12 months without activity. The results of the fifth evaluation indicate the need to resume intervention.

\section{Acknowledgements}

We wish to thank Mrs. Wu Pi Chun, Bruna Terumi Sato Yonamine, Celso Antônio de Souza Mello, Eneida Bulle de Oliveira, Maria Teresa Dias, Diogo Brito Calado and Altay Alves Lino de Souza for their invaluable help. This 
project was undertaken by volunteer researchers, without funding.

\section{Disclosure Statement}

There is no conflict of interest to declare.

\section{Funding}

Scholarship from CAPES Foundation, Ministry of Education of Brazil, BrasiliaDF 70040-020, Brazil. In process. 11/06/2332.

\section{References}

[1] Dalakas, M. and Illa, I. (1991) Post-Polio Syndrome: Concepts in Clinical Diagnosis, Pathogenesis, and Etiology. Advances in Neurology, 56, 495-511.

[2] Secretaria de Estado da Saúde de São Paulo (2006) Síndrome pós-poliomielite. $R e$ vista de saude publica, 40, 941-945. https://doi.org/10.1590/S0034-89102006000600029

[3] Abe, G.C., Ramos, P.E., Fontes, S.V., Yonamine, B.T.S., Mello, C.Ad.S., Quadros, A.A.J., et al. (2011) Poliomielite e síndrome pós-poliomielite pela Medicina Tradicional Chinesa: Do diagnóstico aos mecanismos fisiopatolo gicos. Revista Neurociências, 19, 365-381.

[4] Balzien, B., Hofner, B., Harlander-Weikert, E., Frommelt, P., Bork, H., Forst, R., et al. (2014) Orthopadische Beschwerden und Funktionseinschrankungen beim Post-Polio-Syndrom. [Musculoskeletal Symptoms in Patients with Post-Polio Syndrome.] Zeitschrift Fur Orthopadie Und Unfallchirurgie, 152, 241-246. https://doi.org/10.1055/s-0034-1368531

[5] Quadros, A.A., Conde, M.T., Marin, L.F., Silva, H.C., e Silva, T.M., de Paula, M.B., et al. (2012) Frequency and Clinical Manifestations of Post-Poliomyelitis Syndrome in a Brazilian Tertiary Care Center. Arquivos de Neuro-Psiquiatria, 70, 571-573. https://doi.org/10.1590/S0004-282X2012000800002

[6] Oliveira, A.S.B. and Quadros, A.A.J. (2008) Síndrome Pós-Poliomielite (SPP): Orientações para Profissionais de Saúde. CCD/SES-SES/SP, São Paulo.

[7] Oliveira, A.S.B. and Maynard, F.M. (2002) Síndrome pós-poliomielite: Aspectos neurológicos. Revista Neurociências, 10, 31-34.

[8] Departamento de Atenção Básica, Secretaria de Atenção à Saúde, Ministério da Saúde, Brasil (2006) Política Nacional de Práticas Integrativas e Complementares no SUS. Ministério da Saúde, Brasília, 96 p.

[9] Yang, H.-P. (2006) The Textual Research of What "Shuo Wen Jie Zi Xi Zhuan" Quoted Ancient Books. Journal of Ancient Books Collation and Studies, 2, 29-32.

[10] Mulder, D.W. (1995) Clinical Observations on Acute Poliomyelitis. Annals of the New York Academy of Sciences, 753, 1-10. https://doi.org/10.1111/j.1749-6632.1995.tb27526.x

[11] Ramos, P.E., Abe, G.C., Pradella-Hallinan, M., Quadros, A.A., Schmidt, B. and Oliveira, A.S. (2012) Effects of Daoyin Qigong in Postpolio Syndrome Patients with Cold Intolerance. Arquivos de neuro-psiquiatria, 70, 680-685. https://doi.org/10.1590/S0004-282X2012000900006

[12] Barbosa, V. and Stewien, K.E. (1980) Aspectos de importância para a vigilância epidemiológica da poliomielite na cidade de São Paulo, Brasil. Revista de saude publica, 14, 557-568. https://doi.org/10.1590/S0034-89101980000400011 
[13] Borella, Md.P. and Sacchelli, T. (2009) Os efeitos da prá tica de atividades motoras sobre a neuroplasticidade. Revista Neurociências, 17, 161-169.

[14] Fisher, B.E. and Sullivan, K.J. (2003) Activity-Dependent Factors Affecting Poststroke Functional Outcomes. Topics in Stroke Rehabilitation, 8, 31-44. https://doi.org/10.1310/B3JD-NML4-V1FB-5YHG

[15] Gonzalez-Alonso, J., Mortensen, S.P., Jeppesen, T.D., Ali, L., Barker, H., Damsgaard, R., et al. (2008) Haemodynamic Responses to Exercise, ATP Infusion and Thigh Compression in Humans: Insight into the Role of Muscle Mechanisms on Cardiovascular Function. The Journal of Physiology, 586, 2405-2417. https://doi.org/10.1113/jphysiol.2008.152058

[16] Gonzalez-Alonso, J., Olsen, D.B. and Saltin, B. (2002) Erythrocyte and the Regulation of Human Skeletal Muscle Blood Flow and Oxygen Delivery: Role of Circulating ATP. Circulation Research, 91, 1046-1055. https://doi.org/10.1161/01.RES.0000044939.73286.E2

[17] Kirby, B.S., Voyles, W.F., Carlson, R.E. and Dinenno, F.A. (2008) Graded Sympatholytic Effect of Exogenous ATP on Postjunctional Alpha-Adrenergic Vasoconstriction in the Human Forearm: Implications for Vascular Control in Contracting Muscle. The Journal of Physiology, 586, 4305-4316. https://doi.org/10.1113/jphysiol.2008.154252

[18] Rosenmeier, J.B., Hansen, J. and Gonzalez-Alonso, J. (2004) Circulating ATP-Induced Vasodilatation Overrides Sympathetic Vasoconstrictor Activity in Human Skeletal Muscle. The Journal of Physiology, 558, 351-365. https://doi.org/10.1113/jphysiol.2004.063107

[19] Rosenmeier, J.B., Yegutkin, G.G. and Gonzalez-Alonso, J. (2008) Activation of ATP/UTP-Selective Receptors Increases Blood Flow and Blunts Sympathetic Vasoconstriction in Human Skeletal Muscle. The Journal of Physiology, 586, 4993-5002. https://doi.org/10.1113/jphysiol.2008.155432

[20] Pearson, J., Low, D.A., Stöhr, E., Kalsi, K., Ali, L., Barker, H., et al. (2011) Hemodynamic Responses to Heat Stress in the Resting and Exercising Human Leg: Insight into the Effect of Temperature on Skeletal Muscle Blood Flow. American Journal of Physiology. Regulatory, Integrative and Comparative Physiology, 300, R663-R673. https://doi.org/10.1152/ajpregu.00662.2010

[21] São Paulo (2013) Prefeitura Municipal de São Paulo. http://www.cidadedesaopaulo.com/sp/br/clima

[22] Estação Meteorológica do IAG/USP (2013) Informações sobre as Estações do Ano na Cidade de São Paulo São Paulo-Brasil: Estação Meteorológica do IAG/USPSeção Técnica de Serviços Meteorológicos.

http://www.estacao.iag.usp.br/seasons/index.php

[23] Horvath, S.M., Radcliffe, C.E., Hutt, B.K. and Spurr, G.B. (1955) Metabolic Responses of Old People to a Cold Environment. Journal of Applied Physiology, 8, 145-148. https://doi.org/10.1152/jappl.1955.8.2.145

[24] Watts, A.J. (1972) Hypothermia in the Aged: A Study of the Role of Cold-Sensitivity. Environmental Research, 5, 119-126. https://doi.org/10.1016/0013-9351(72)90025-4

[25] Sugarek, N.J. (1986) Temperature Lowering after Iced Water. Enhanced Effects in the Elderly. Journal of the American Geriatrics Society, 34, 526-529. https://doi.org/10.1111/j.1532-5415.1986.tb04245.x

[26] Collins, K.J. (1987) Effects of Cold on Old People. British Journal of Hospital Medicine, 38, 506-508. 